\title{
OPTIMIZATION OF PROCESS PARAMETERS OF FRICTION STIR WELDING
}

\section{OF AA 6082-T6 USING GREY BASED TAGUCHI METHOD}

\section{N. RAVINDER REDDY ${ }^{1}$, V. V. SATYANARAYANA ${ }^{2}$, G AMBIKA ${ }^{3} \&$ S. PRASAD KUMAR ${ }^{4}$ \\ ${ }^{1}$ Associate Professor, Department of Mechanical Engineering, Vidya Jyothi Institute of Technology,}

Aziznagar, Hyderabad, Telangana, India

${ }^{2}$ Professor, Department of Mechanical Engineering, Vidya Jyothi Institute of Technology,

Aziznagar, Hyderabad, Telangana, India

${ }^{3,4}$ Assistant Professor, Department of Mechanical Engineering, Vidya Jyothi Institute of Technology,

Aziznagar, Hyderabad, Telangana, India

\begin{abstract}
Friction stir welding process is a mushy state joining technique and is extensively used for unification of similar and dissimilar metals employed for aerospace, automobile and other fabrication industries. Friction stir welding gives improved mechanical and metallurgical characteristics in the nugget zone in contrast with the conventional welding processes. In this study, three main factors, each at two levels are employed during experiment; The responses measured in the study include hardness, Impact toughness and percentage elongation and are converted into grey values. The optimal permutation of parameters has been found by the Taguchi Grey relational analysis.

KEYWORDS: Friction Stir Welding, Optimization, Taguchi, Grey Relational Analysis, Analysis of Variance (ANOVA), Grey Relational coefficient
\end{abstract}

Received: Nov 22, 2017; Accepted: Dec 13, 2017; Published: Jan 06, 2018; Paper Id.: IJMPERDFEB201840

\section{INTRODUCTION}

The fusion welding operations are in high energy inducing joining processes and cause wider heat affected zones and inflict solidification defects; and these processes are not particularly suitable for aluminum and magnesium based alloys. AA6082-T6 is an aluminum alloy, with magnesium and silicon elements as other major constituents, employed in aerospace industries, because of its high strength to weight ratio. Friction stir welding (FSW), being a solid state welding process characterized by low heat input and is capable of giving rise to joints having mechanical properties on par with base metals, employed for joining of aluminum alloys. In the Friction stir welding process, the necessary heat for joining of the two metals is generated by a rapidly rotating non consumable tool pin extending from a cylindrical shoulder plunged at the joint interface of the metals to be joined (Figure 1)[1].

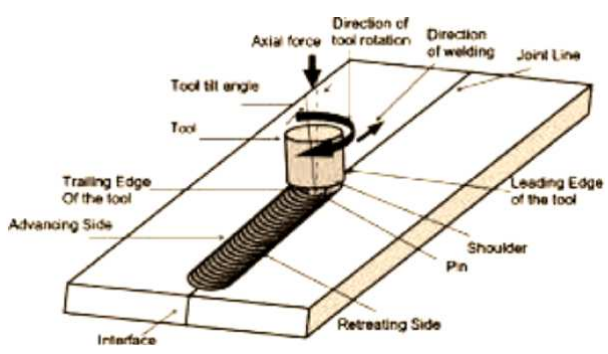

Figure 1: Friction Stir Welding Process 
The Friction stir welding process is governed by various governing parameters viz tool speed, rotational speed, angle of tilt of tool, geometry of tool, etc. while the responses evaluated are the strength of the joint, impact toughness, hardness, bend ductility etc. As a result, the study becomes a multi-response optimization problem that requires a systematic approach to ascertain the number of experiments to be conducted in order to cover the entire domain of input parameters.

Following Grey Taguchi approach, a multi-response problem shall be converted into a single response using the weight factors of gray relational analysis [2]. This technique is a deductive process and evaluates the output explicit values in order to determine the implicit system characteristics [3, 4].

Friction stir welding of AA 7075 aluminum alloys is undertaken for estimation of fatigue life [5] and noticed dissolution of precipitates in the weld region. The nugget zone is often characterized by fine grains, while thermo mechanically affected zone is softened in the Friction stir welds of 2219 aluminum alloys [6]. Process parameter optimization by grey relational analysis for AA 6061 alloys was undertaken in FSW [7]. A study to optimize power consumption along with tensile strength of joints was undertaken for 5083 aluminum alloy friction welding process.[8] The effect of welding parameters on mechanical and metallurgical properties of AA 6082 T6 FSW butt joints are studied and optimized the parameters combination [9]. FSW of dissimilar AA 2024 - AA 5052 welding was undertaken by changing the geometry of tool pin and studied the mechanical and metallurgical properties [10]

In this investigation, Friction stir welding of AA6082-T6 alloy is undertaken and the analysis is conducted employing grey based Taguchi method.

\section{EXPERIMENTAL INVESTIGATION}

\section{Materials}

The material employed is AA 6082-T6 aluminum alloy plates made to size $160 \mathrm{X} 80 \mathrm{X} 8 \mathrm{~mm}$ for the butt welding Joint by Friction stir welding process. The Chemical composition and mechanical properties of the metal are given in Table 1 and Table 2 respectively.

Table 1: Chemical Composition of AA6082 T6alloy

\begin{tabular}{|l|l|l|l|l|l|l|l|l|}
\hline $\mathbf{M g}$ & $\mathbf{S i}$ & $\mathbf{F e}$ & $\mathbf{C u}$ & $\mathbf{Z n}$ & $\mathbf{T i}$ & $\mathbf{M n}$ & $\mathbf{C r}$ & $\mathbf{A l}$ \\
\hline 0.8 & 0.9 & 0.2 & 0.05 & 0.09 & 0.05 & 0.8 & 0.02 & Balance \\
\hline
\end{tabular}

Table 2: Mechanical Properties of AA6082 T6 Alloy

\begin{tabular}{|c|c|c|c|c|}
\hline $\begin{array}{c}\text { Yield } \\
\text { Strength (Mpa }\end{array}$ & $\begin{array}{c}\text { Ultimate } \\
\text { Strength (MPa) }\end{array}$ & Elongation (\%) & $\begin{array}{c}\text { Reduction in Cross } \\
\text { Section Area (\%) }\end{array}$ & Hardness (VHN) \\
\hline 290 & 340 & 11 & 12.24 & 90 \\
\hline
\end{tabular}

\section{Friction Stir Welding Machine}

Welding process is carried out on Eta Technology make 40 KVA Friction stir welding machine. The experiments are conducted in a random manner in order to avoid any kind of error or bias. The machine has the capability to make the joints up to $1000 \mathrm{~mm}$ length.

\section{Welding Parameters}

The welding machine has the provision to change the parameters rotational speed, weld speed and tool tilt angle 
while keeping the other parameters constant during experimentation. Trial runs are held and the range of parameters is identified in the respective domains. The Table 3 shows the parameters employed for experimentation in the present investigation.

Table 3: Process Parameters

\begin{tabular}{|c|l|c|c|c|}
\hline SI No. & \multicolumn{1}{|c|}{ Parameters } & Notation & Low level (1) & High level (2) \\
\hline 1 & Tool Rotational Speed (rpm) & A & 1100 & 1700 \\
\hline 2 & Weld Speed (mm/min) & B & 300 & 500 \\
\hline 3 & Tool Tilt Angle (degrees) & C & 1.5 & 2.5 \\
\hline
\end{tabular}

\section{Taguchi Experimental Orthogonal Array}

In this investigation with the chosen three control parameters, each at 2 level are taken for making the weld joints and hence L8 orthogonal array is selected accordingly (Table 4).

Table 4: L8 Orthogonal Array

\begin{tabular}{|c|c|c|c|}
\hline Run & A & B & C \\
\hline 1 & 1 & 1 & 1 \\
\hline 2 & 1 & 1 & 2 \\
\hline 3 & 1 & 2 & 1 \\
\hline 4 & 1 & 2 & 2 \\
\hline 5 & 2 & 1 & 1 \\
\hline 6 & 2 & 1 & 2 \\
\hline 7 & 2 & 2 & 1 \\
\hline 8 & 2 & 2 & 2 \\
\hline
\end{tabular}

\section{Grey Relational Analysis}

The grey relational analysis associated with Taguchi method is based on random uncertainty of small samples having incomplete information. The experimental results are first normalized in the range between zero and unity; after that the grey relational coefficients are obtained from the normalized experimental data to express the relationship between the desired and actual experimental data. Finally, the overall grey relational grade is computed from the arithmetic average of the grey relational coefficients corresponding to each run. Thus, multiple response optimization problems are converted into single response problem with the objective function of overall grey relational grade. The optimum process parameter condition is arrived at the highest grey relational grade. The responses have been targeted for higher the better characteristic, the normalization is done by

$$
\mathrm{X}_{\mathrm{i}}(\mathrm{k})=\frac{y_{i}(k)-\min y_{i}(\mathrm{k})}{\max y_{i}\left(\mathrm{w}^{-\min } y_{i}(k)\right.}
$$

Similarly, lower the better characteristic, normalization is performed by

$$
X_{i}(k)=\frac{\max y_{i}(k)-y_{i}(k)}{\max y_{i}\left(k i-\min y_{i}(k)\right.}
$$

Where, $y_{i}(k)$ is the original reference sequence, $x_{i}(k)$ is the sequence for comparison $i=1,2$----m and $k=1,2$-----$\mathrm{n}$ with $\mathrm{m}$ and $\mathrm{n}$ being the total number of experiments and responses respectively. The $\min y_{i}(k)$ is the smallest value of $y_{i}$ (k) and max $\mathrm{y}_{\mathrm{i}}(\mathrm{k})$ is the highest value of $\mathrm{y}_{\mathrm{i}}(\mathrm{k})$. Here, $x_{i}(k)$ is the value computed after the grey relational generation with ideal sequence of $x_{0}(k)$. The grey relational grade revealed the relational degree between the experimental run sequences 
$\left[x_{0}(k)\right.$ and $\left.x_{i}(k), i=1,2, \ldots m\right]$.

The grey relational coefficient $\xi_{i}(k)$ could be calculated as

$\xi i(k)=\frac{\psi \Delta_{\max }+\Delta_{\min }}{\Delta_{i 0}(k)+\psi \Delta_{\max }}$

Where, $\Delta_{0 i}=\left\|x_{0}(k)-x_{i}(k)\right\|$

$\Delta_{0 i}$ is the difference of the absolute value between $\mathrm{x}_{0}(\mathrm{k})$ and $x_{\mathrm{i}}(k) . \Delta \min$ and $\Delta$ max are the minimum and maximum values of the absolute differences of all comparing sequences. The purpose of distinguishing coefficient $\psi(0 \leq$ $\psi \leq 1$ ) was to weaken the effect of $\Delta \max$ when it became too large. In the present analysis, the value of $\psi$ was taken as 0.5 in order to give a moderate weight age.

\section{RESULTS AND ANALYSIS}

The welding of the materials chosen is undertaken employing the parameters at their levels as pronounced in the L8 orthogonal array (Table 4). For consistency, the experiments are repeated twice and the average of the evaluated responses is recorded. The weld Joints which have been subjected to mechanical property evaluation are considered for three responses viz elongation (\%) in tension test, micro hardness and Impact toughness (Table 5).

Table 5: Experimental Results

\begin{tabular}{|c|c|c|c|}
\hline Run & $\begin{array}{c}(\mathbf{\%}) \\
\text { Elongation }\end{array}$ & $\begin{array}{c}\text { Micro Hardness } \\
(\mathbf{H v})\end{array}$ & $\begin{array}{c}\text { Impact Toughness } \\
\text { (joules) }\end{array}$ \\
\hline 1 & 11.4 & 87 & 20.3 \\
\hline 2 & 10.3 & 85 & 19 \\
\hline 3 & 9.6 & 86 & 19.5 \\
\hline 4 & 10.2 & 90 & 18 \\
\hline 5 & 8.9 & 92 & 15.6 \\
\hline 6 & 5.8 & 91 & 14.8 \\
\hline 7 & 4.9 & 93 & 14 \\
\hline 8 & 6.3 & 95 & 15 \\
\hline
\end{tabular}

Among these, the responses elongation and impact toughness are targeted for higher the better characteristic, while the micro hardness is targeted for lower the better characteristic; the normalization of these data have been performed accordingly and compiled in Table 6.

Table 6: Normalized Responses

\begin{tabular}{|c|c|c|c|}
\hline Run & (\%) Elongation & Hardness & Impact Toughness \\
\hline 1 & 1 & 0.8 & 1 \\
\hline 2 & 0.8307 & 1 & 0.7936 \\
\hline 3 & 0.723 & 0.9 & 0.873 \\
\hline 4 & 0.815 & 0.5 & 0.6345 \\
\hline 5 & 0.6154 & 0.3 & 0.253 \\
\hline 6 & 0.1384 & 0.4 & 0.1263 \\
\hline 7 & 0 & 0.2 & 0 \\
\hline 8 & 0.2153 & 0 & 0.1587 \\
\hline
\end{tabular}

The normalized data so computed have been converted into grey relational coefficients after making into ideal sequences and employing the distinguishing coefficient. The resultant grey relational coefficient of each of these responses is given in Table 7. 
Table 7: Grey Relation Coefficient

\begin{tabular}{|c|c|c|c|}
\hline Run & \% Elongation & Hardness & Impact Toughness \\
\hline 1 & 1 & 0.7142 & 1 \\
\hline 2 & 0.747 & 1 & 0.7078 \\
\hline 3 & 0.6435 & 0.833 & 0.797 \\
\hline 4 & 0.7299 & 0.5 & 0.5843 \\
\hline 5 & 0.5652 & 0.4166 & 0.4166 \\
\hline 6 & 0.3672 & 0.4545 & 0.3639 \\
\hline 7 & 0.3333 & 0.3846 & 0.3333 \\
\hline 8 & 0.3891 & 0.3333 & 0.3727 \\
\hline
\end{tabular}

The average of the grey relational coefficients of the responses is termed as total relational grade (TGR) computed in a single response form for the data undertaken and is given in Table 8.

Table 8: Total Grey Relational Grade (TGR)

\begin{tabular}{|c|c|}
\hline Run & TGR \\
\hline 1 & 0.9047 \\
\hline 2 & 0.8182 \\
\hline 3 & 0.7578 \\
\hline 4 & 0.6047 \\
\hline 5 & 0.4661 \\
\hline 6 & 0.3952 \\
\hline 7 & 0.3504 \\
\hline 8 & 0.3650 \\
\hline
\end{tabular}

The TGR values are now subjected to Analysis of variance (Table 9) using Yates algorithm [11]. The parameter rotational speed $(\mathrm{A})$ is contributing to a tune of $83.58 \%$ in the achievement of all the responses, while the remaining two parameters are contributing insignificantly. The priority of these parameters in their rank order and the levels of these optimal parameters are given in Table 10 and are shown in Figure 2.

Table 9: Analysis of Variance

\begin{tabular}{|c|c|c|c|c|c|}
\hline Source & DF & Adj SS & Adj MS & F- Value & \% Contribution \\
\hline A & 1 & 0.28452 & 0.284522 & 88.31 & 83.58 \\
\hline B & 1 & 0.03204 & 0.032042 & 9.95 & 9.4 \\
\hline C & 1 & 0.01289 & 0.010945 & 3.40 & 3.786 \\
\hline Error & 4 & 0.01289 & 0.003222 & & \\
\hline Total & 7 & 0.34040 & & & \\
\hline
\end{tabular}

Table 10: Optimal Parameter Identification of TGR

\begin{tabular}{|c|c|c|c|c|c|}
\hline Factors & Level 1 & Level 2 & Max - Min & Rank & Optimum level \\
\hline A & 0.7714 & 0.3942 & 0.3198 & 1 & 1 \\
\hline B & 0.6461 & 0.5194 & 0.1266 & 2 & 1 \\
\hline C & 0.6197 & 0.5457 & 0.074 & 3 & 1 \\
\hline
\end{tabular}

\section{DISCUSSIONS}

High impact toughness is recorded, when all the parameters are at low level while lower magnitudes of toughness have obtained when the parameters are at higher levels. The percentage elongation during tension test is in higher magnitudes, when the tool rotational speed is maintained at low level and vice versa. 


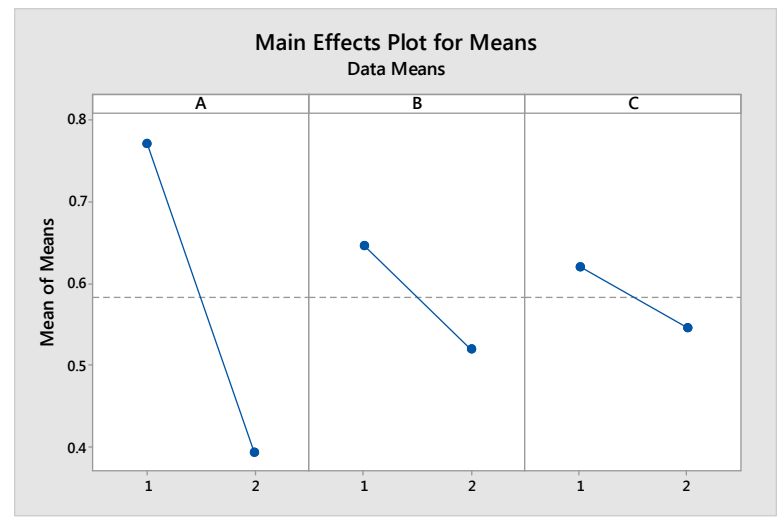

Figure 2: Main Effects of Parameters

The elongation and toughness values are dependent on the weld rotational speed indicating the development of requisite heat for joint preparation. The microstructure at the nugget zone (Figure 3) shows the grains are dynamically recrystallized and hence possess the higher toughness values. The hardness values are in reverse trend as compared to other mechanical properties.

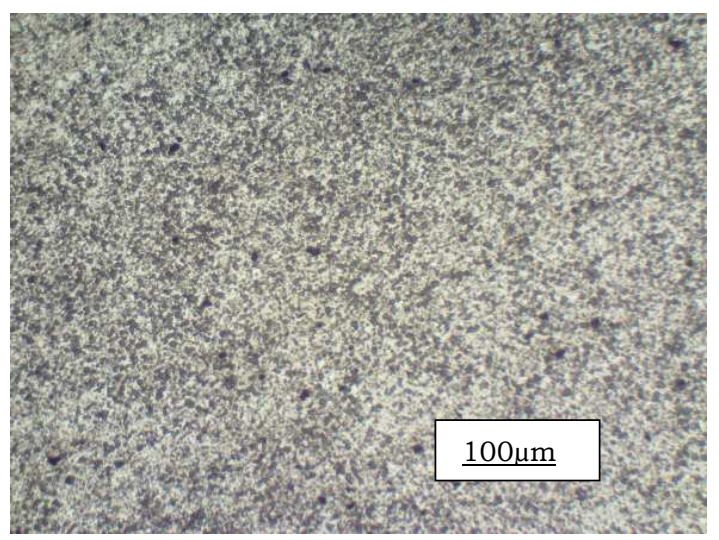

Figure 3: Microstructure at Nugget

\section{CONCLUSIONS}

The optimal conditions indicate that the elongation and impact toughness of the FSW Joints of AA 6083-T6 alloy are dependent on the parameters at a particular level only due to the generation of requisite heat for coalescence and setting of the joint. Hardness values are in inverse relation with other mechanical properties in line with ferrous material joints.

The grey relational analysis is found to be effective, when there are more number of responses which are diverse in nature and whenever the sampling involves more uncertainity.

\section{REFERENCES}

1. Thomas WM, Threadgil PL, ED Nicholas "Feasibility of Friction Stir welding steel J of material property Technology 178, 342-349.

2. Y Кио T. yang and GW Huang, "The use of grey based Taguchi method for opetimizing multi response simulation problems", engineers optimization Vole 40, No.6 pp 517-528, 2008.

3. Hasani H, Tabatabaei SA, Amiri G (2012) Grey relational analysis to determine the optimum process parameters for open-end spinning yarns. J Eng Fiber Fabr 7:81-86 
4. Huang JT, Liao YS (2003) Optimization of machining parameters of wire-EDM based on Grey relational and statistical analyses. Int J Prod Res 41:1707-1720.

5. Fatigue static properties of FSW aluminium using triflute type and smooth tool ", Archies of Metallugy and Materials, pp 157172.

6. S. Krishnakumar et al., Evaluation of Machinability of D2 Steel using Cryo Treated Cermet using Taguchi Technique, International Journal of Mechanical and Production Engineering Research and Development (IJMPERD), Volume 7, Issue 3, May - June 2017, pp. 7-16

7. Ch Venkat Rao, G Madhusudhan Reddy, K Srinivas Rao, "Influence of tool pin profile on microstructure and corrosion ehaviour of AA 2219 Al-cu friction stir weld nuggets", Defene Technology, 11 (3), 2015, pp 197-208.

8. P. Prasanna, Dr. Ch. Penchalayya, Dr. D. Anandamohana Rao "Optimization and Validation of Process Parameters in Friction Stir Welding on AA 6061 Aluminum Alloy Using Gray Relational Analysis” International Journal of Engineering Research and Applications (IJERA) ISSN: 2248-9622.

9. VIJAYAN S. Multi objective optimization of friction stir welding process parameters on aluminum Alloy AA 5083 using Taguchi based grey relation analysis [J]. Materials and Manufacturing Processes, 2010, 25, 1206-1212.

10. G Raghubabu, KGK Murthi, G Rangajanardhan "An experimental study on effect of welding parameter on mechanical and micro structural properties of AA 608.2-T6 friction stir welded butt joints", ARPN Journal of Engineering and Applied Sciences, 3 (5), 2008, pp 68-74.

11. Venkateshkannan, M., Rajkumar, V., Sadeesh, P., Arivazhagan, N., Narayanan, S., \& Ramkumar, K. D. (2014). Influences of Tool Geometry on Metallurgical and Mechanical Properties of Friction Stir Welded Dissimilar AA 2024 and AA 5052. Procedia Engineering, 75, 154-158.

12. DC Montgomery, (2001), Design and analysis of experiments, $4^{\text {th }}$ ed, New York, Jhon wiley \& sons 
